\title{
Cut Out Complications and Anisomelia of the Lower Limbs in Surgery with Valgus Reduction for Intertrochanteric Fractures
}

\section{Abstract}

Background: The proximal fractures of the femur are counted among the group of orthopedic and traumatic pathologies which consume most of the financial resources set aside for health worldwide. Surgical treatment continues to be the treatment of choice for intertrochanteric fractures of the femur. However, although the surgical treatment of the proximal fracture of the femur is widely known and accepted in the orthopedic field, it is not without risk with the cut out being the most feared complication.

Objective: This paper describes the complications of cut out or the anisomelia of the lower limbs of patients with intertrochanteric fractures who underwent valgus reduction surgery.

Methods: Sixty-one patients with 3rd and 4th degree, according to Tronzo classification, intertrochanteric fractures underwent surgery with the use of Dynamic hip screw type sliding screw and valgus reduction. The data were analyzed one year after surgery, when a functional assessment was made by scanometry, Tip-Apex Distance index diaphyseal cervical angle and the modified Merle d'Aubigné \& Postel questionnaire. Kruskal-Wallis and Mann-Whitney tests were used for the statistical analysis, Spearman's correlation test for the quantitative variables and the chi-squared test for the qualitative variables.

Results: The correlation between the Tip-Apex Distance index and the diaphyseal cervical angle was statistically significant ( $r h o=0.391$, $p=0.002$ ), while the correlations between the Tip-Apex Distance index and the scanometry and the diaphyseal cervical angle and the scanometry were not significantly correlated. In accordance with the modified Merle d'Aubigné \& Postel questionnaire, 23 patients (37.7\%)
Takeshi Chikude ${ }^{1}$, Edison Noboru Fujiki ${ }^{1}$, Luiz Carlos de Abreu², Fernando Adami², Vitor Engrácia Valenti², Italla Maria Pinheiro Bezerra², Fernando Rocha Oliveira2 Dorian Riker Telles de Menezes Jr ${ }^{1}$, Roberto Yukio Ikemoto', Luciano Miller Reis Rodrigues ${ }^{1,2}$, Carlo Milani ${ }^{1}$

1 Disciplina de Doenças do Aparelho Locomotor da Faculdade de Medicina do $A B C$

2 Laboratório de Delineamento de Estudos e Escrita Científica. Disciplina de Metodologia Científica. Faculdade de Medicina do ABC.

Contact information:

Luiz Carlos de Abreu.

$\equiv$ luiz.abreu@fmabc.br 
achieved a very good result, 29 patients (47.5\%) had a good result, five patients (8.2\%) obtained a moderately good result, one patient $(1.6 \%)$ presented a reasonable result and three patients $(4.9 \%)$ obtained a poor result.

Conclusion: No cut out complications occurred in the 3rd and 4th degree intertrochanteric fractures with a Baumgaertner index $\geq 25$ $\mathrm{mm}$, when the reduction and valgus fixation of the intertrochanteric fracture was performed with the Dynamic hip screw type sliding pin, as there was also, in the majority of patients, no anisomelia of the lower limbs.

\section{Keywords}

Fractures of the femur; Orthopedic Surgery; Orthopedic fixation devices; Fracture fixation; Post-operative complications; Elderly

\section{Background}

Fractures in the proximal region of the femur, out of all osteoporotic fractures, present a great impact and greater severity as a direct cause or aggravation of morbid-mortality, or the social dependence of the elderly coupled with their functional restriction. The need for additional assistance for the activities of daily life occur in $50 \%$ of patients with this type of fracture, beyond which their life expectancy may be reduced by up to $25 \%$, thus greatly harming their quality of life [1].

Proximal fractures of the femur are counted among the group of orthopedic and traumatic pathologies which, worldwide, account for the greatest drain on financial resources set aside for health [2]. It is estimated that the number of hip fractures in the world to exceed six million people by the year 2050 . Of the resources reserved for the orthopedic field in Brazil, these fractures belong to the group of nine pathologies of the locomotor apparatus which consume about $90 \%$ of the total financial budget, according to a survey by the Ministry of Health [3-5].

The occurrence of this type of fracture is related to anisotropy, to the disorganization of the microarchitecture of the trabecular structure and to greater bone fragility resulting from the reduction of mineral density of the bone associated with the aging process in men and post-menopausal osteoporosis in women [3]. The incidence of hip fractures, when adjusted for age and sex, you can display geographical, seasonal and racial differences. It is for this reason that these fractures are classified as osteoporotic, due to bone fragility or insufficiency, and are thus occasioned by low-energy traumatisms, most frequently due to falls from the patient's own height [2]. Surgery continues to be the treatment of choice for intertrochanteric fractures of the femur, with the primordial objective being to mobilize and get the patient out of bed as soon as possible so as to reduce the risk of complications. However, although the surgical treatment of the proximal fracture of the femur is widely known and accepted in the orthopedic field, it is not without risk; the cut out is the most feared complication - this can be conceived as the collapse of the diaphyseal cervical angle, the head entering the varus position leading to the extrusion of the screw through the femoral head [6].

Discussion continues regarding the best type of graft with a wide range of grafts developed for the treatment of this kind of fracture; noteworthy among these is the proximal intermedulary shafts and the sliding Dynamic Hip Screw (DHS) [6]. 


\section{Objective}

This paper seeks to describe the complications of cutout or anisomelia of the lower limbs in patients with intertrochanteric fractures who have undergone valgus reduction surgery.

\section{Methods}

\section{Population}

A study was undertaken with patients, interned in the Hospital Mário Covas of the ABC School of Medicine (Faculdade de Medicina do $A B C$ ) and of the Hospital Ipiranga - Unified Health System (Sistema Único de Saúde) of São Paulo city, with intertrochanteric fracture treated surgically during the period from April 2006 to January 2010. The sample consisted of 61 patients, 21 (34.4\%) men and 40 (65.6\%) women.

For division of patients according to the type of fracture a classification system was applied. The most frequently described in the literature for trochanteric fractures are the classifications Tronzo; Evans; Boyd-Griffin [7].

The inclusion method used in the study was classified Tronzo's (1973), it has well-defined characteristics for each type of fracture it and shows a clear differentiation of stable and unstable fractures, type I and II (stable) or III, IV and V (unstable) as described [8].

- I- Incomplete, with only the greater trochanter fracture;

- II-Without fracture comminution, no or slight deviation;

- III- Posterior comminution with the telescoping neck spur in the medullary canal, the small trochanter fragment is large;

variant (III b)- posterior comminution with the telescoping neck spur in the medullary canal, but with a transverse fracture through the greater trochanter
- IV-Comminution of the rear wall without telescoping of the two major fragments such that the spur of the cervix is diverted out of the diaphysis;

- $\mathrm{V}$ - Obliquity reverse.

The inclusion criteria regarding the type of fracture were individuals with $3 \mathrm{~A}$ and $3 \mathrm{~B}$ type unstable intertrochanteric fractures or class 4 according to Tronzo's (1973) criterion were included [8].

Individuals who presented one or more of the following characteristics were excluded from the study: presence of tumoral fractures, fractures associated with diaphysis and the distal femur, bilateral fractures of the hip, fracture or previous surgery in the same hip fracture or previous surgery in the same hip and death in the first post-operative year.

The volunteers were duly informed regarding the procedures and objectives of this study, and after agreeing to participate, signed a form of voluntary, informed consent authorizing their participation. This research project was approved by the Ethics Committee of the $A B C$ Medical School (Faculdade de Medicina do $A B C$ - FMABC), under the protocol number 364/2007.

\section{Protocol}

The data for this present study were obtained on a registration form by the doctor/researcher responsible for each volunteer and on the basis of his or her case-notes, specific tests and complementary examinations, together with personal data and preoperative, surgical act, post-operative and clinical assessment.

The patients were assessed one-year post-operatively on the following aspects: consolidation, presence or absence of anisomelia of the lower limbs by scanometry, diaphyseal cervical angle, Tip-Apex Distance (TAD) index in accordance with Baumgaertner et al. [9], both by the X-ray of the anteroposterior pelvis and by the X-ray of the hip profile, and the modified Merle d'Aubigné and Postel questionnaire. 
X-ray images were taken of the anteroposterior pelvis with the patient in the dorsal decubitus position with the lower limbs at $15^{\circ}$ internal rotation and also of the affected hip in profile with the patient in the dorsal decubitus position with the hip flexed at $90^{\circ}$ and abduction of $45^{\circ}$, in the outpatient department of the hospital. After the analysis of the fracture, a new X-ray of the anteroposterior pelvis was taken with the ray focused on the pubic symphysis, and with the patient in the dorsal decubitus position, with the lower limbs at $15^{\circ}$ internal rotation and traction of the affected member to make the classification of the fracture possible, also in the outpatient department of the hospital.

Scanometry, assessing the difference between the lower limbs, was undertaken one year postoperatively by means of radiography [10] .The TAD index was calculated to verify the possibility of cut out [10]. The diaphyseal cervical angle (also known as the angle of inclination) is the angle that the longitudinal shaft of the femoral neck makes with the longitudinal shaft of the diaphysis of the femur. The criteria from the modified questionnaire of Merle d' Aubigné and Postel were used for functional assessment [11].

\section{Surgical technique}

A synthesis of the DHS of $135^{\circ}$, radioscopy, traction table and valgus reduction was used in all cases. Valgus reduction was represented by a diaphyseal cervical angle equal to or greater than 140 degrees.

From the second day of hospitalization, respiratory and motor physiotherapy of the upper members was applied to all the patients. After the second post-operative day, as well as the respiratory and motor physiotherapy of the upper members, motor physiotherapy with active and passive movement of the lower limbs was performed. Assisted partial load was encouraged from the second postoperative day. The stitches were removed on the tenth post-operative day.
Of the 61 patients, 55 (90.2\%) underwent antithrombotic prophylaxis with subcutaneous Enoxaparin Sodium $40 \mathrm{mg}$ once daily from the first day of hospitalization until the seventh post-operative day; in six patients (9.8\%) 5000 subcutaneous units of Heparin were applied every 12 hours from the first day of hospitalization to the seventh post-operative day. Treatment with anticoagulant was interrupted for all the patients $12 \mathrm{~h}$ before the operation. Cutaneous traction was used on all the patients during the pre-operative period.

\section{Statistical treatment}

Frequency tables, measurements of central tendency and of dispersion were used to describe the data. The statistical tests used included KruskalWallis, Mann-Whitney, and Spearman's correlation for quantitative variables and the chi-squared test for qualitative variables.

Spearman's correlation test was used for the analysis of the correlation between the TAD index and the diaphyseal cervical angle; the Mann-Whitney test was used for the analysis of the correlation between the TAD index $\leq 24 \mathrm{~mm}$ and the diaphyseal cervical angle and the TAD index $\geq 25 \mathrm{~mm}$ and the diaphyseal cervical angle; the Kruskal-Wallis test was used for the analysis of the diaphyseal cervical angle and anisomelia and the TAD index and anisomelia; and the chi-squared test was used to analyze TAD $\leq 24 \mathrm{~mm}$ with anisomelia and TAD $\geq 25 \mathrm{~mm}$ with anisomelia. A 5\% significance level was adopted.

\section{Results}

The patients presented an average age and standard deviation of $80.2 \pm 9.9$ years, ranging from 47 to 96 years. The average and standard deviation of the diaphyseal cervical angle were $149.7 \pm$ 10.6 ranging from 140 and 180, with the diaphyseal cervical angle being relatively large. The TAD index was relatively high with an average of $27.7 \mathrm{~mm}$. The distance between the apex of the femoral head and 


\section{INTERNATIONAL ARCHIVES OF MEDICINE \\ Section: Traumatology and Orthopedics \\ ISSN: 1755-7682}

the distal end of the screw on the anteroposterior radiograph showed a mean and standard deviation of $13.9 \pm 4.8 \mathrm{~mm}$ ranging from $4.0 \mathrm{~mm} 28.0 \mathrm{~mm}$. The distance between the apex of the head in lateral view and the distal end of the screw showed an average and standard deviation of $14.0 \pm 4.9 \mathrm{~mm}$ ranging from $5.0 \mathrm{~mm}$ and $25.0 \mathrm{~mm}$. One-year postoperative anisomelia in centimeters presented an average and standard deviation of $0.21 \pm 0.42$ ranging from $0.5 \mathrm{~cm}$ to $2.5 \mathrm{~cm}$.

The characteristics of the individuals who underwent treatment for intertrochanteric fractures are provided in Tables 1 to 6 .

Table 1 shows the distribution of the patients who underwent intertrochanteric fracture surgery with valgus reduction with regard to the following variables: sex, predominant place of pre-operative ambulation, presence of associated disease, classification of the fracture in accordance with Tronzo's classification,[8] side of the fracture and degree of damage (Table 1).

Table 1. Distribution of patients who underwent intertrochanteric fracture surgery with valgus reduction.

\begin{tabular}{|l|c|c|}
\hline \multicolumn{1}{|c|}{ Variables } & Frequency (n) & Percentage (\%) \\
\hline Sex & & \\
\hline Males & 21 & 34.4 \\
\hline Females & 40 & 65.6 \\
\hline Predominant place of pre-operative ambulation \\
\hline Indoor & 24 & 39.3 \\
\hline External & 28 & 45.9 \\
\hline Active external & 9 & 14.8 \\
\hline Presence of associated disease & \\
\hline Yes & 45 & 73.8 \\
\hline No & 16 & 26.2 \\
\hline Fracture classification & & \\
\hline 1 & 0 & 0.0 \\
\hline 2 & 0 & 0.0 \\
\hline $3 A$ & 33 & 54.1 \\
\hline $3 B$ & 26 & 42.6 \\
\hline 4 & 2 & 3.3 \\
\hline 5 & 0 & 0.0 \\
\hline & & \\
\hline & &
\end{tabular}

\begin{tabular}{lcc} 
Side of fracture & & \\
\hline Right & 35 & 57.4 \\
Left & 26 & 42.6 \\
\hline Level of damage * * & & 90.2 \\
\hline $\begin{array}{l}\text { Unilateral } \\
\text { Bilateral }\end{array}$ & 55 & 0.0 \\
\hline Systemic \# & 0 & 9.8 \\
\hline * Tronzo's[5] classification & 6 & \# Alteration in other joint \\
& or systemic disease which \\
affects gait
\end{tabular}

In the sample, the return to former physical activities occurred in $88.5 \%$ of the cases, the lower limbs were equalized $(70.5 \%)$, with no post-operative complication (98.4\%), without pain (59.0\%) or with only discrete pain at the beginning of the resumption of movement which diminished with exercise activity (39.3\%), normal gait (31.1\%) or limping gait with no need for a walking-stick (39.3\%) and grade 5 mobility (68.9\%). The only complication was an infection in one patient (Table 2).

Table 2. Distribution of patients who underwent intertrochanteric fracture surgery with valgus reduction.

\begin{tabular}{|l|c|c|}
\multicolumn{1}{|c|}{ Variables } & $\begin{array}{c}\text { Frequency } \\
\text { (n) }\end{array}$ & $\begin{array}{c}\text { Percentage } \\
\text { (\%) }\end{array}$ \\
\hline Return to physical activities & & \\
\hline No & 7 & 11.5 \\
Yes & 54 & 88.5 \\
\hline Anisomelia & & \\
\hline Shortening & 5 & 8.2 \\
\hline Equalizing & 43 & 70.5 \\
\hline Lengthening & 13 & 21.3 \\
\hline
\end{tabular}

\section{Presence of post-operative complications}

Yes

No

60

98.4

Classification of post-operative pain after one year * *

\begin{tabular}{|l|l|l}
\hline Intense spontaneous pain (1) & 0 & 0.0
\end{tabular}

$\begin{array}{lll}\text { Intense pain upon walking (2) } & 0 & 0.0\end{array}$

Tolerable pain with limited

activity (3)

0.0

Pain after activity, disappearing with rest (4) 
Pain at the beginning of walking, diminishing with activity(5)

Without pain(6)

24

36

59.1

Classification of functionality of gait after one year **

Few meters or bedridden; uses

walking sticks or crutches(1)

3

4.9

Limited in time and distance

with or without walking stick

0

0.0

(2)

\section{Limited with walking}

stick, tolerates prolonged

2

3.3

orthostatism (3)

Walks a long way with walking

stick (4)

Limps, without crutches (5)

13

21.3

Normal (6)

24

39.3

19

31.1

Classification of post-operative mobility after one year ** $0^{\circ}-30^{\circ}(1)$ 0

$31^{\circ}-60^{\circ}(2)$

$61^{\circ}-100^{\circ}(3)$

0

$101^{\circ}-160^{\circ}(4)$ 11

$161^{\circ}-210^{\circ}(5)$

0.0

$211^{\circ}-260^{\circ}(6)$

Total

7

61

0.0

1.6

18.0

68.9

11.5

61

100.0

** Classification of by Merle \& Postel modified by Charnley d'Aubigné

The average values of the TAD index and the diaphyseal cervical angle in the groups of shortening, equalizing and lengthening showed no statistical differences (Table 3).

As observed in Table 4, there was no statistically significant association between classification in accordance with the TAD index and scanometry. Thus, the use of the valgus reduction technique in intertrochanteric fracture surgery permits variation in the TAD index and the diaphyseal cervical angle without interfering in the length of the lower limbs (Table 4).

Table 5 shows that there were no statistically significant differences in the average values of the diaphyseal cervical angle in the groups classified in accordance with the TAD index. The average of the diaphyseal cervical angle was thus independent of the value of the TAD index (Table 5).

In Table 6, the correlation between the TAD index and the diaphyseal cervical angle was statistically significant ( $r h o=0.391, p=0.002$ ), while the correlations between the TAD index and scanometry and the angle and scanometry were not significantly correlated (Table 6). Thus, the greater the diaphyseal cervical angle, the greater the TAD index, indicating that as the angle increased, the positioning of the sliding screw became increasingly difficult (Table 6).

In accordance with the Merle d'Aubigné and Postel questionnaire as modified by Charnley (1972): 55 patients (90.2\%) were type $A$, six patients (9.8\%) were type C; 23 patients (37.7\%) obtained a very good result, 29 patients (47.5\%) had a good result, five patients $(8.2 \%)$ obtained an intermediate result, one patient (1.6\%) presented a reasonable result and three patients (4.9\%) obtained a poor result [12].

Table 3. Distribution of patients by TAD category and scanning.

\begin{tabular}{|c|c|c|c|c|c|}
\hline \multirow{2}{*}{ TAD Index } & \multicolumn{3}{|c|}{ Scanning } & \multirow{2}{*}{ Total } & \multirow{2}{*}{$p *$} \\
\hline & Shortening & Equalization & Lengthening & & \\
\hline \multirow{2}{*}{$<$ or $=24 \mathrm{~mm}$} & 3 & 13 & 4 & 20 & \multirow{4}{*}{0.400} \\
\hline & $15.0 \%$ & $65.0 \%$ & $20.0 \%$ & $100.0 \%$ & \\
\hline \multirow{2}{*}{$>$ or $=25 \mathrm{~mm}$} & 2 & 30 & 9 & 43 & \\
\hline & $4.9 \%$ & $73,2 \%$ & $21.9 \%$ & $100.0 \%$ & \\
\hline \multirow{2}{*}{ Total } & 5 & 43 & 13 & 61 & \\
\hline & $8.2 \%$ & $70.5 \%$ & $21.3 \%$ & $100.0 \%$ & \\
\hline * Chi-squared test. & \multicolumn{5}{|c|}{ Legend: $\mathrm{mm}=$ millimeters } \\
\hline
\end{tabular}




\section{INTERNATIONAL ARCHIVES OF MEDICINE \\ Section: Traumatology and Orthopedics \\ ISSN: 1755-7682}

Vol. 8 No. 49

doi: $10.3823 / 1648$

Table 4. Measures of central tendency and dispersion according to TAD, cervico-diaphyseal angle and scanning.

\begin{tabular}{|c|c|c|c|c|c|c|}
\hline Variable & Scanning & n & Average $\pm S D$ & Minimum & Maximum & $p * *$ \\
\hline \multirow{4}{*}{ TAD $(m m)$ index * } & Shortening & 5 & $25.4 \pm 10.0$ & 12.0 & 38.0 & \multirow{4}{*}{0.590} \\
\hline & Equalization & 43 & $27.6 \pm 8.3$ & 9.0 & 47.0 & \\
\hline & Lengthening & 13 & $28.9 \pm 10.2$ & 15.0 & 48.0 & \\
\hline & Shortening & 5 & $145.00 \pm 7.1$ & 140.0 & 155.0 & \\
\hline \multirow{2}{*}{ Cervico- diaphyseal angle $\left(^{\circ}\right)$} & Equalization & 43 & $150.07 \pm 10.5$ & 140.0 & 180.0 & \multirow{2}{*}{0.799} \\
\hline & Lengthening & 13 & $150.15 \pm 12.3$ & 140.0 & 180.0 & \\
\hline \multicolumn{7}{|c|}{$\begin{array}{l}\text { * TAD Index }=\text { the distance from the tip of the screw to the apex of the femoral head in the anteroposterior and posterior } \\
\text { incidences. }\end{array}$} \\
\hline ** Kruskal-Wallis Test. & & & \multicolumn{4}{|c|}{$\begin{array}{l}\text { Legend: } \mathrm{mm}=\text { millimeters; } \mathrm{SD}=\text { standard deviation; } \\
\qquad \mathrm{n}=\text { absolute number; }{ }^{\circ}=\text { degrees. }\end{array}$} \\
\hline
\end{tabular}

Table 5. Measures of central tendency by TAD category and cervico-diaphyseal angle.

\begin{tabular}{|c|c|c|c|c|}
\hline Variables & TAD Index* (mm) & $\mathbf{n}$ & Average \pm SD & $p^{* *}$ \\
\hline \multirow{2}{*}{ Cervico- diaphyseal angle $\left(^{\circ}\right)$} & $<25.0$ & 20 & $146.1 \pm 6.6$ & \multirow{2}{*}{0.127} \\
\hline & $>$ or $=25.0$ & 41 & $151.4 \pm 11.8$ & \\
\hline \multicolumn{5}{|c|}{$\begin{array}{l}\text { * TAD Index = the distance from the tip of the screw to the apex of the femoral head in the } \\
\text { anteroposterior and posterior incidences. }\end{array}$} \\
\hline \multicolumn{2}{|l|}{ ** Mann-Whitney Test. } & \multicolumn{3}{|c|}{$\begin{array}{l}\text { Legend: } \mathrm{mm}=\text { millimeters; } \mathrm{SD}=\text { standard deviation; } \\
\qquad{ }^{\circ}=\text { degrees }\end{array}$} \\
\hline
\end{tabular}

Table 6. Correlation between TAD, scanning and cervico-diaphyseal angle by TAD and cervico-diaphyseal angle.

\begin{tabular}{|c|c|c|c|}
\hline Pair of variables & $\mathrm{n}$ & Correlation Coefficient & $p * *$ \\
\hline TAD * $(\mathrm{mm})$ vs scanning $(\mathrm{cm})$ & 61 & +0.081 & 0.537 \\
\hline Angle $\left(^{\circ}\right)$ vs scanning $(\mathrm{cm})$ & 61 & +0.064 & 0.622 \\
\hline TAD * $(\mathrm{mm})$ vs angle $\left(^{\circ}\right)$ & 61 & +0.391 & $0.002^{\#}$ \\
\hline \multicolumn{2}{|c|}{$\begin{array}{l}\text { * TAD Index = the distance from the tip of } \\
\text { the screw to the apex of the femoral head in } \\
\text { the antero-posterior and posterior incidences. }\end{array}$} & \multicolumn{2}{|l|}{ ** Spearman's correlation test } \\
\hline \multicolumn{2}{|c|}{ \# Statistically significant difference $(p<0.05)$. } & \multicolumn{2}{|c|}{$\begin{array}{l}\text { Legend: } \mathrm{mm}=\text { millimeters; } \mathrm{cm}=\text { centimeters; } \\
\qquad{ }^{\circ}=\text { degrees; } \mathrm{n}=\text { absolute number }\end{array}$} \\
\hline
\end{tabular}

\section{Discussion}

The present research project sought to describe the cut out complications and anisomelia of the lower limbs in patients with intertrochanteric fractures who underwent valgus reduction surgery.

As demonstrated in Table 1, a predominance of female patients was observed (65.6\%) as compared to males (34.4\%), together with the predominance of intertrochanteric fractures in females as also observed in the studies by Nieves et al. [13.] It is believed that this incidence is related to the fact that women possess a smaller percentage of muscle than men - which is common after climacteric. Further, the presence of associated disease was observed in $73.8 \%$ of the patients, among whom there were three cases, only detected after hospitalization, of asymptomatic urinary infection detected by the pre-operative Urine 1 examination 
and treated with Ciprofloxacin. The high incidence of associated disease corroborates the findings of the study undertaken by Johnell et al. [14] showing that this kind of complication is frequent in patients with intertrochanteric fracture, highlighting the indispensability of attention to care for these patients.

Regarding types 3A, 3B and 4 unstable intertrochanteric Tronzo (1973) fractures, in this present study there was a greater incidence of type 3A Tronzo fractures (in $54.1 \%$ of the patients), followed by type 3B Tronzo fractures (42.6\%) and lastly by type 4 Tronzo fractures (3.3\%) [15].

As for the hemisphere of the fractures observed, $57.4 \%$ of the intertrochanteric fractures occurred on the patients' right side, which differed from Mohan et al. [16] who found a predominance of the left side, though those authors demonstrated that no cut out or pseudarthrosis occurred, regardless of the side of the fracture. The side of the occurrence of the intertrochanteric fracture can directly influence the result of treatment because, when the cephalic head of the DHS is inserted, the rotational clockwise torque tends to displace the intertrochanteric fracture of the left femur and reduce that of the right [16].

Another factor assessed by this study was the patients' return to physical activities. It was ascertained that 54 patients (88.5\%) returned to their former activities while 7 patients (11.5\%) did not succeed in this, as shown in Table 2 . The same finding may be observed in the study conducted by Chirodian et al. [14] who discovered that the majority of patients operated on with DHS returned to their previous activities within a year of the operation. However, surgical success is not necessarily tantamount to functional success seeing that a considerable number of patients do not recover to their pre-fracture ambulatory condition, highlighting the fact that early mobilization is fundamental for avoiding associated complications $[15,17]$.
In accordance with the classification of Merle d'Aubigné and Postel modified by Charnley (1972) [9] provided in Table 2, 1 patient (1.6\%) presented grade 4 post-surgical pain after one year, 24 patients (39.3\%) grade 5 and 36 patients (59.1\%) grade 6 with similar results found by Chirodian et al. [14] with $95 \%$ of patients reporting no or only slight pain. However, in Chirodian and colleagues' study, both stable and unstable intertrochanteric fractures were analyzed in contrast with our study in which unstable 3 and 4 Tronzo intertrochanteric fractures were investigated. In the assessment of gait, we found in our study that after one year, 3 patients (4.9\%) presented grade 1, 2 patients (3.3\%) grade 3, 13 patients (21.3\%) grade 4, 24 patients $(39.3 \%)$ grade 5, 19 patients $(31.1 \%)$ grade 6, thus agreeing with Chirodian (2005). The assessment of one-year post-surgical mobility showed that 1 patient (1.6\%) was grade 3, 11 patients $(18.0 \%)$ grade 4,42 patients $(68.9 \%)$ grade 5 , and 7 patients $(11.5 \%)$ grade $6[7,17]$.

In the classification according Merle d'Aubigné and Postel as modified by Charnley (1972) [12], 23 patients $(37.7 \%)$ obtained a very good result, 29 patients $(47.5 \%)$ had a good result, five patients (8.2\%) obtained an intermediate result, one patient $(1.6 \%)$ had a reasonable result and three patients $(4.9 \%)$ a poor result; however, all the patients consolidated and none presented any cut out complication.

The variation of the TAD index is considered a predictive factor of complications, together with the diaphyseal cervical angle. In Table 3, neither of these variables interfered with the length of the lower limbs which were, in the majority of cases (70.5\%), equalized. This reinforces the idea that despite the valgus tending to lengthen the member, the impaction tends to shorten it, thus neutralizing the lengthening. The fact that the greater the diaphyseal cervical angle, the greater the TAD index, shows that the increase in the diaphyseal cervical angle hinders the passage of the sliding 
DHS in the head of the femur, though it does make consolidation without the occurrence of cut out possible, seeing that in this situation the shear forces are converted into compression forces, favoring consolidation, as described by Fujiki et al. [6].

A study conducted by Baumgaertner et al. [18] demonstrated that when the TAD index is greater than or equal to $25 \mathrm{~mm}$, there is a tendency for cut out complications to occur, though no such complication was observed in this current study, even in those patients who presented a TAD index greater than $25 \mathrm{~mm}$, when associated with a valgus reduction - as depicted in Table 3. The valgus should, theoretically, lengthen the lower limbs, however, for a great majority of patients (70.5\%), the length of the lower limbs was equalized, probably by virtue of the effect of the impact on the fracture.

When the diaphyseal cervical angle and TAD were analyzed as seen in Table 4, there was no significance in the valgus reduction when the diaphyseal cervical angle considered was greater than or equal to $140^{\circ}$. All the fractures consolidated, suggesting that the valgus provides a reduction in the incidence of fixation failures, thus corroborating the reports by Koberle et al. [3] and Fujiki et al. [6]. The varus predisposes a loss of fixation as demonstrated by Rao et al. [19] and a loss of reduction as demonstrated by Malkani \& Karandikar [20].

The correlation between the TAD index and the diaphyseal cervical angle presented in Table 6 was statistically significant ( $r h o=0.391, p=0.002$ ). The TAD index was high, with an average of $27.7 \mathrm{~mm}$, suggesting that the valgus reduction hinders the introduction of the sliding DHS screw in the femoral head.

The literature showed that the type of fracture can affect the occurrence of complications; generally fractures considered stable present a much lower complication rate than the unstable ones. The choice of graft, a good reduction and the exact placement of the graft with an adequate surgical technique are factors which lead to a reduction in post-surgical complications of unstable fractures [12]. In types $A 1$ and $A 2$, the DHS plate, when compared to cephalomedular shafts, produces similar results with regard to time of radioscopy, surgical time, blood loss, duration of hospitalization, post-operative mobility, mortality and functional result [21]. However, the DHS plate does not result in fracture of the diaphysis as a complication, which is related to the Gamma Nail pin; the DHS plate is, therefore, still recommended for A1 and A2 type fractures. On the other hand, for reverse trace type $A 3$ fractures, the use of cephalomedular shafts may be advantageous,[22] while for the stable intertrochanteric fractures DHS is the best fixation method.

In accordance with Canto et al., [15] no advantage was observed in undertaking osteotomies associated with osteosynthesis and their use is not recommended for unstable intertrochanteric fractures. In this present study valgus reduction was used, although it was unnecessary to undertake osteotomy in any of the patients.

In comparative studies and presents good results observed for both systems, but in stable fractures there is no apparent advantage of one over the other, whereas for unstable fractures cephalomedular systems are preferable to open reduction is required, and results tend to favor the sliding attachment with pins/plates. But both surgical time and bleeding are similar[23].

Endo et al. [24] discovered greater mortality among men than among women in the period of at least one post-surgical year in cases of hip fracture. Cornwall et al. [25] ascertained that $13.8 \%$ of patients with intertrochanteric fracture died within six months.

The study of a technique which might favor consolidation and avoid cut out is very interesting. Campbell et al. [26] highlighted the difficulty encountered in the treatment of fractures with failure 
in the method using DHS. However, cut-out does not only occur with the use of DHS. Lucke et al. [27] reported cases of cut out with the use of Gamma Nail, together with intrapelvic migration. Gotfried (2004) showed the importance of maintaining the integrity of the trochanteric lateral wall for reducing post-operative morbidity in intertrochanteric fractures [28].

In comminuted fractures associated with lateral cortical fractures, the fixation is frequently difficult, as described by Yoo et al. (2000) who practiced fixation with a $95^{\circ}$ angled plate. In this present study, this preoccupation was less probably because the impaction associated with the valgus favors consolidation due to the rise of compression forces [295].

Branlet et al. [31] in a retrospective study of the surgical treatment of intertrochanteric fractures using the talon hip compression screw, found no cut out, though they did use anatomical reduction, thus corroborating the findings of this present study in which valgus reduction was used and no cut out was observed. There have been modifications of the DHS screw such as that described by Bramlet \& Wheeler (2003), with a hip compression screw with retractable hooks, in the attempt to make consolidation easier and diminish the incidence of cut out. In this present research the artifact of reduction in valgu was used to diminish cut out and facilitate consolidation [31].

The fact that Batoniček et al. [32] undertook intertrochanteric valgus osteotomy on four patients with intertrochanteric varus pseudoarthrosis and that all of them consolidated suggests that the valgus makes the consolidation of the fractures easier, corroborating the results of our study in which all the patients with valgus reduction presented consolidation of the fractures.

\section{Conclusion}

There was no cut out complication in the 3rd and 4th grade Tronzo fractures with a Baumgaertner index $\geq 25 \mathrm{~mm}$, when the reduction and valgus fixation of the intertrochanteric fracture was effected with the sliding DHS type pin, nor was there any anisomelia of the lower limbs in the majority of the patients.

\section{References}

1. Balasegaram S, Majeed A, Fitz-Clarence H: Trends in hospital admissions for fractures of the hip and femur in England, 19891990 to 1997-1998. J Public Health Med 2001, 23(1): 11-17.

2. Saudan M, Lubbeke A, Sadowski C, Riand N, Stern R, Hoffmeyer $P$ : Pertrochanteric fractures: is there an advantage to an intramedullary nail?: a randomized, prospective study of 206 patients comparing the dynamic hip screw and proximal femoral nail. J Orthop Trauma 2002,16(6): 386-393.

3. McCarthy, J. C. "SUBCAPITAL FRACTURES: A CHANGING PARADIGM." Bone \& Joint Journal Orthopaedic Proceedings Supplement. 2013. 95(22): 16.

4. Koberle G: Fraturas intertrocantéricas. Rev Bras Ortop 2001, 36(9): 325-329.

5. Brauer CA, Coca-Perraillon M, Cutler DM, Rosen AB. Incidence and mortality of hip fractures in the United States. JAMA 2009; 302: 1573

6. Fujiki EN, Honda EK, Ohara GH: Estudo prospectivo e comparativo das fraturas intertrocantéricas, tratadas com o pino-parafuso de Pinto de Souza e parafuso deslizante DHS. Acta Ortop Bras 1994, 2: 143-148.

7. Behrendt C, Faleiro TB, Schulz RDS, Silva BOD, Paula EQD. Repruducibility of tronzo and ao/asif classifications for transtrochanteric fractures. Acta Ortopedica Brasileira 2014;22(5):275-277. doi:10.1590/1413-78522014220500884

8. Tronzo RG (Ed): Surgery of the hip joint. Philadelphia Lea and Febiger; 1973.

9. Baumgaertner M, Curtin S, Lindskog D, Keggi J: The value of the tip-apex-distance in predicting failure of fixation of peritrochanteric fractures of the hip. J Bone Joint Surg Am 1995, 77(7): 1058-1064

10. Werlang HZ, Oliveira GA, Tamelini AM, Madalosso BH, Maciel Jr FS: Escanometria dos membros inferiores: revisitando Dr. Juan Farril. Radiol Bras 2007, 40(2): 137-141.

11. Ugino FK, Righetti CM, Alves DPL, Guimarães RP, Honda EK, Ono NK: Avaliação da confiabilidade do método Merle D'Aubigné e Postel Modificado. Acta Ortop Bras 2012, 20(4): 213-217. 
12. Charnley J. The long-term results of low-friction arthroplasty of the hip performed as a primary intervention. J Bone Joint Surg Br. 1972; 54B(1): 61-76.

13. Nieves JW, Bilezikian JP, Lane JM, Einhorn TA, Wang Y, Steinbuch $\mathrm{M}$, Cosman F: Fragility fractures of the hip and femur: incidence and patient characteristics. Osteoporos Int 2010, 21(3): 399408.

14. Johnell O, Kanis JA: An estimate of the worldwide prevalence, mortality and disability associated with hip fracture. Osteoporos Int 2006, 17(12): 1726-1733.

15. Canto RST, Sakaki M, Susuki I, Tucci P, Belangero W, Kfuryi Jr M, Skaf AY: Sociedade Brasileira de Ortopedia e Traumatologia. Fratura Intertrocantérica. Rev Assoc Med Bras 2009, 55(6): 631641.

16. Mohan R, Karthikeyan R, Sonanis SV: Dynamic hip screw: Does side make a difference? Effects of clockwise torque on right and left DHS. Injury 2000, 31(9): 697-699.

17. Chirodian N, Arch B, Parker MJ: Sliding Hip Screw Fixation of Trochanteric Hip Fractures: Outcome of 1024 Procedures. Injury 2005, 36(6): 793-800.

18. Baumgartner MR, Solberg BD: Awareness of tip-apex-distance reduces failure of fixation of trochanteric fractures of the hip. J Bone Joint Surg Br 1997, 79(6): 969-971.

19. Rao JP, Banzon MT, Weiss AB, Rayhack J: Treatment of unstable intertrochanteric fractures with anatomic reduction and compression hip screw fixation. Clin Orthop Relat Res 1983, 175: 65-71.

20. Malkani AL, Karandikar N: Revision fixation for failed intertrochanteric fractures. Techniques in Orthopaedics 2002, 17(4): 443-447.

21. Jones HW, Johnston $P$, Parker M: Are short femoral nails superior to the sliding hip screw? A meta-analysis of 24 studies involving 3,279 fractures. Int Orthop 2006, 30(2): 69-78.

22. Olsson O, Ceder L, Hauggaard A: Femoral shortening in intertrochanteric fractures. A comparison between the Medoff sliding plate and the compression hip screw. J Bone Joint Surg $\mathrm{Br}$ 2001, 83(4): 572-578

23. Papasimos $S$, Koutsojannis CM, Panagopoulos $A$, Megas $P$, Lambiris $E$. A randomised comparison of $A M B I, T G N$ and PFN for treatment of unstable trochanteric fractures. Arch Orthop Trauma Surg 2005; 125: 462-8.

24. Endo Y, Aharonoff GB, Zucherman JD, Egol KA, Koval KJ: Gender differences in patients with hip fracture: a greater risk of morbidity and mortality in men. J Orthop Trauma 2005, 19(1): 29-35.

25. Cornwall R, Gilbert MS, Koval KJ, Strauss E, Siu AL: Functional outcomes and mortality vary among different types of hip fractures. Clin Orthop Relat Res 2004, 425: 64-71.

26. Campbell AC, Goyal S, Miller NJK, Sinha S: New technique for revising dynamic hip screw fixations with lag screw in situ. J Orthop Trauma 2010, 24(10): 653-655.
27.Lucke M, Burghardt RD, Siebenlist S, Ganslmeier A, Stockle $\mathrm{U}$ : Medial migration of lag screw with intrapelvic dislocation in gamma nailing - a unique problem? A report of 2 cases. J Orthop Trauma 2010, 24(2): e6-e11.

28. Gotfried Y: The lateral trochanteric wall. Clin Orthop Relat Res 2004, 425: 82-86

29. Yoo MC, Cho YJ, Kim Kl, Khairuddin M, Chul YS: Treatment of unstable peritrochanteric femoral fractures using a 95-degree angled blade plate. J Orthop Trauma 2005, 19(10): 687-692.

30. Branlet DG: Use of the talon hip compression screw in intertrochanteric fractures of the hip. Clin Orthop Relat Res 2004, 425: 93-100.

31. Bramlet DG, Wheeler D: Biomechanical evaluation of a new type of hip compression screw with retractable talons. J Orthop Trauma 2003, 17(9): 618-624.

32. Bartoníček J, Skála-Rosenbaum J, Dousa P: Valgus intertrochanteric osteotomy for malunion and nonunion of trochanteric fractures. J Orthop Trauma 2003, 17(9): 606-612.

33. Thorngren K-G: National registration of hip fractures in Sweden. In European Instructional Lectures. Edited by Bentley G. 2009, 9: $11-18$

\section{Comment on this article:}

\section{$f(B)$ in $8+\&$}

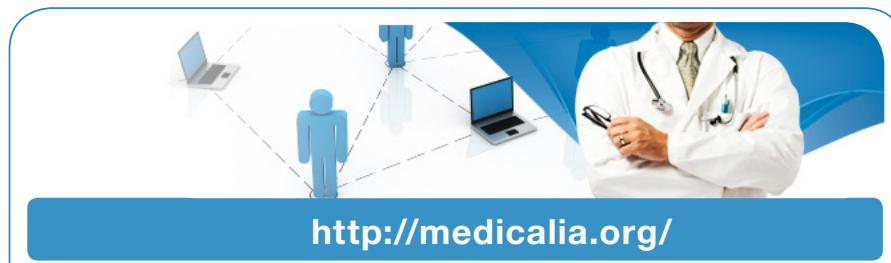

Where Doctors exchange clinical experiences, review their cases and share clinical knowledge. You can also access lots of medical publications for free. Join Now!

\section{Publish with iMedPub}

\section{http://www.imed.pub}

International Archives of Medicine is an open access journal publishing articles encompassing all aspects of medical science and clinical practice. IAM is considered a megajournal with independent sections on all areas of medicine. IAM is a really international journal with authors and board members from all around the world. The journal is widely indexed and classified Q1 in category Medicine. 